\title{
Cytoplasmic p21 WAF1/CIP1 expression is correlated with HER-2/neu in breast cancer and is an independent predictor of prognosis
}

\author{
Zoë E Winters ${ }^{1}$, Russell D Leek ${ }^{2}$, Mike J Bradburn ${ }^{3}$, Chris J Norbury ${ }^{4}$ and Adrian L Harris ${ }^{4}$ \\ 1 University Department of Surgery, Bristol Royal Infirmary, University of Bristol, UK \\ ${ }^{2}$ Cancer Research UK Tumour Pathology Group, University of Oxford, Nuffield Department of Clinical Laboratory Sciences, John Radcliffe Hospital, \\ Oxford, UK \\ ${ }^{3}$ Cancer Research UK Medical Statistics Group, Centre for Statistics in Medicine, Institute of Health Sciences, Oxford, UK \\ ${ }^{4}$ Cancer Research UK Molecular Oncology Laboratories, Weatherall Institute of Molecular Medicine, John Radcliffe Hospital, Oxford, UK
}

Correspondence: ZE Winters (e-mail: zoe.winters@bristol.ac.uk)

Received: 9 Jun 2003 Revisions requested: 30 Jul 2003 Revisions received: 29 Aug 2003 Accepted: 2 Sep 2003 Published: 3 Oct 2003

Breast Cancer Res 2003, 5:R242-R249 (DOI 10.1186/bcr654)

(C) 2003 Winters et al., licensee BioMed Central Ltd (Print ISSN 1465-5411; Online ISSN 1465-542X). This is an Open Access article: verbatim copying and redistribution of this article are permitted in all media for any purpose, provided this notice is preserved along with the article's original URL.

\begin{abstract}
Background HER-2 (c-erbB2/Neu) predicts the prognosis of and may influence treatment responses in breast cancer. HER-2 activity induces the cytoplasmic location of p21 WAFI/CIPI in cell culture, accompanied by resistance to apoptosis. p21WAFI/CIPI is a cyclin-dependent kinase inhibitor activated by p53 to produce cell cycle arrest in association with nuclear localisation of p21 WAFI/CIPI. We previously showed that higher levels of cytoplasmic p21WAFI/CIPI in breast cancers predicted reduced survival at 5 years. The present study examined HER-2 and $\mathrm{p} 21_{\mathrm{WAFI} / \mathrm{CIPI}}$ expression in a series of breast cancers with up to 9 years of follow-up, to evaluate whether in vitro findings were related to clinical data and the effect on outcome.

Methods The CB11 anti-HER2 monoclonal antibody and the DAKO Envision Plus system were used to evaluate HER-2 expression in 73 patients. p2 $1^{\text {WAFI/CIPI }}$ staining was performed as described previously using the mouse monoclonal antibody Ab-1 (Calbiochem, Cambridge, MA, USA).

Results HER-2 was evaluable in 67 patients and was expressed in $19 \%$ of cases, predicting reduced overall survival $(P=0.02)$ and reduced relapse-free survival $(P=0.004$; Cox regression model). HER-2-positive tumours showed proportionately higher cytoplasmic p21WAFI/CIPI staining using an intensity distribution score (median, 95) compared with HER-2-negative cancers (median, 47) $(P=0.005)$. There was a much weaker association between nuclear p21WAFI/CIPI and HER-2 expression $(P=0.05)$, suggesting an inverse relationship between nuclear $\mathrm{p} 21^{\text {WAF1/CIP1 }}$ and HER-2.

Conclusion This study highlights a new pathway by which HER-2 may modify cancer behaviour. HER-2 as a predictor of poor prognosis may partly relate to its ability to influence the relocalisation of $\mathrm{p} 21^{W A F I / C I P I}$ from the nucleus to the cytoplasm, resulting in a loss of $\mathrm{p} 21$ WAFI/CIPI tumour suppressor functions. Cytoplasmic p21WAFI/CIPI may be a surrogate marker of functional HER-2 in vivo.
\end{abstract}

Keywords: CDK inhibitor, immunohistochemistry, phosphatidylinositol-3 kinase/protein kinase $B$, prognostic markers

\section{Introduction}

HER-2 is one of four Erb B family-type I receptor tyrosine kinases and is the preferred dimerisation partner for the epidermal growth factor receptor [1,2]. The Erb B receptors are important in normal development and in human cancer. HER-2, independent of its own ligand, activates other Erb B receptors to increase their ligand affinity and to amplify biological responses. HER-2 plays a key role in activating cytoplasmic signalling through the phosphatidylinositol-3 kinase (PI-3K)/protein kinase $B$ (Akt) and mitogen-activated protein kinase pathways to influence transcription of nuclear genes [2-4]. Activation of $\mathrm{PI}-3 \mathrm{~K} / \mathrm{Akt}$ is involved in cell proliferation and confers resistance to apoptosis $[5,6]$. Breast cancer is associated with

$A k t=$ protein kinase $B ; C D K=$ cyclin-dependent kinases; ELISA = enzyme-linked immunosorbent assay; ER = oestrogen receptor; IDS $=$ intensity distribution score; NPI = Nottingham Prognostic Index; OS = overall survival; PI-3K = phosphatidylinositol-3 kinase; RFS = relapse-free survival. 
deregulated expression of HER-2, detectable as HER-2 amplification or protein overexpression identified in $10-40 \%$ of tumours [7]. HER-2 expression is indicative of poor prognosis and may predict tumour responses to hormone therapy and chemotherapy.

Cell cycle progression is regulated by cyclin-dependent kinases (CDKs) associated with cyclin proteins. p21WAF1/CIP1, a downstream target of p53, is a CDK inhibitor that re-enforces p53-mediated $\mathrm{G} 1$ and $\mathrm{G} 2$ arrest following genotoxic insults, to facilitate DNA repair [8-11]. The integrity of $\mathrm{G} 1$ and $\mathrm{G} 2$ checkpoints requires the nuclear localisation of p21WAF1/CIP1 [11,12]. Recent evidence including subcellular fractionation suggests that p21WAF1/CIP1 can localise in the cytoplasm in cancer tissues and cell lines, where it inhibits apoptosis by binding and inhibiting the apoptosis signal-regulating kinase 1 [13-17]. Such an anti-apoptotic function in breast cancers could underlie the association between cytoplasmic p21WAF1/CIP1 and poor prognosis [17]. Upregulation of p21WAF1/CIP1 occurs through PI-3K/Akt signalling, and may involve insulin-like growth factors, p53-dependent pathways or HER-2 expression [18-20]. A HER-2-overexpressing breast cancer cell line transcriptionally upregulates $\mathrm{p} 21^{\mathrm{WAF} 1 / \mathrm{CIP} 1}$ and has been shown to produce its cytoplasmic localisation through a mechanism whereby Akt binds and phosphorylates p21WAF1/CIP1 in its nuclear localisation signal [21]. In vivo HER-2 expression may involve changes in the subcellular localisation of p21WAF1/CIP1 to influence the outcome in breast cancer.

We previously found that breast cancers with higher levels of cytoplasmic p21WAF1/CIP1 predicted reduced overall survival (OS) and relapse-free survival (RFS), with correlation between cytoplasmic p21WAF1/CIP1 and p53 expression on immunohistochemistry [17]. Recent in vitro findings demonstrated a direct influence of HER-2 on

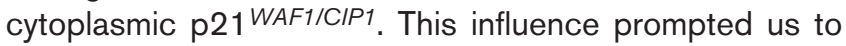
investigate HER-2 expression in a retrospective series of breast cancers with p21WAF1/CIP1 staining by immunohistochemistry and a further 4 years of patient follow-up [21]. We are not aware of any other study to date examining subcellular p21WAF1/CIP1 expression in relation to HER-2 immunoreactivity.

\section{Patients and methods Patients}

The study included 73 patients aged $32-80$ years (median, 55 years) with primary infiltrating carcinoma diagnosed between 1989 and 1992 at the John Radcliffe Hospital. The eligibility criteria were histological diagnosis of breast carcinoma, level one or complete axillary lymph node dissection, no distant metastases and unilateral tumour. Forty-nine $(67 \%)$ cases were node-negative and 24 (33\%) cases were node-positive (N1-mobile ipsilateral or N2-fixed ipsilateral).
Clinicopathological subgroups were analysed according to the Nottingham Prognostic Index (NPI). They were divided into good, moderate and poor prognostic groups as previously described, with a modification that included no assessment of the internal mammary lymph nodes $[22,23]$. Seventeen nongraded nonductal cancers were not included in the NPI groups.

Adjuvant treatment groups comprised tamoxifen (16 nodenegative patients, 14 node-positive patients), cyclophosphamide/methotrexate/5-fluorouracil (six node-negative patients, six node-positive patients), and both tamoxifen plus cyclophosphamide/methotrexate/5-fluorouracil (two node-negative patients, four node-positive patients). Twenty-five node-negative women received no adjuvant treatment.

The median duration of follow-up was 110 months (range, 46-144 months) among patients who were alive at the date of their last visit. Tumour samples were collected shortly after surgery and were fixed in buffered formalin for 24-48 hours at room temperature. Tumours were classified according to Azzopardi [24]. Invasive ductal carcinomas were graded by the modified Bloom's grading system described by Elston and Ellis [25]. The oestrogen receptor (ER) status was determined using an ELISA assay (Abbott-ERICA; Abbott Laboratories, Maidenhead, UK). Tumours were classified as ER-positive if oestradiol binding exceeded $10 \mathrm{fmol} / \mathrm{mg}$ cytosolic protein.

\section{Immunohistochemistry}

HER-2 immunostaining was performed using the mouse monoclonal anti-HER-2 antibody (RTU-CB11) (NovaCastra/ Vector, Newcastle upon Tyne, UK), and the DAKO Envision Plus HRP system (K4006; DAKO, Ely, Cambridgeshire, UK). Formalin-fixed paraffin sections of breast cancer tissue were baked, dewaxed and rehydrated prior to a peroxidase block ( $0.1 \%, v / v$ hydrogen peroxide) and an incubation in $10 \% \mathrm{v} / \mathrm{v}$ normal goat serum. The primary antibody and horseradish peroxide-labelled polymer were used as per the DAKO Envision kit, followed by 3,3-diaminobenzidine and counterstaining with haematoxylin before mounting.

HER-2 expression was scored according to the degree and the proportion of membrane staining [26]. HER-2 expression was negative for a score of 0 or $1+$. A score of 0 was defined as no staining or membrane staining in less than $10 \%$ of tumour cells. A score of $1+$ comprised faint or partly-stained membranes in more than $10 \%$ of tumour tissue. Overexpression of c-erbB2 was scored as 2+, defined as weak to moderate complete membrane staining in more than $10 \%$ of tumour cells. A score of $3+$ was interpreted as strong, complete membrane staining in more than $10 \%$ of tumour. This was analysed in the Department of Clinical Laboratory Sciences (by RDL). 
p21WAF1/CIP1 immunoreactivity was evaluated using the mouse monoclonal antibody Ab-1 (Calbiochem, Cambridge, MA, USA) at $0.5 \mu \mathrm{g} / \mathrm{ml}$. Biotinylated goat antimouse IgG (DAKO, Glostrup, Denmark) secondary antibody was used at $15 \mu \mathrm{g} / \mathrm{ml}$. The Strept ABC Duet kit (DAKO, Denmark) was used for p21WAF1/CIP detection [17]. Immunostaining was assessed using a Laborlux microscope (Leitz, Wetzlar, Germany) at 400x overall magnification with a field diameter of $0.46 \mathrm{~mm}$. p21WAF1/CIP1 immunoreactivity was assessed as the degree of staining intensity and the proportion of cells with p21WAF1/CIP1 in the nucleus and in the cytoplasm, which was graded semiquantitatively to produce an intensity distribution score (IDS) for each localisation [17]. Calculation of the IDS was performed as follows: IDS (maximum score $300)=1 \times$ per cent of weakly stained cells $+2 \times$ per cent of moderately stained cells $+3 \times$ per cent of strongly stained cells. Average IDS values were determined by examination of 10 fields [17].

\section{Statistical analysis}

The association between HER-2 and patient characteristics was assessed using the Mann-Witney test for continuous variables and the chi-squared test for categorical factors. The relationship between HER-2 and the subcellular localisation of p21WAF1/CIP1 was analysed using the Mann-Witney $U$ test, with the p21WAF1/CIP1 IDS used as a continuous variable. Analyses of survival data were performed using the log-rank test and the Cox regression model, with survival curves computed using the Kaplain-Meier method.

For both HER-2 and p21WAF1/CIP1 markers univariate and multivariate analyses were performed, the latter adjusting for the NPI score and the treatment received (tamoxifen/ chemotherapy/no treatment). As the NPI is based on nodal involvement, on tumour size and on grade, patients with histologies for whom grade is undefined ('other' cancers) were excluded from the regression analyses. Thirteen patients (all either ductal carcinoma, lobular carcinoma or mixed histology) had no grade information recorded in the data and one patient had no tumour size recorded. These patients were included in the analysis using multiple imputation methods [27] to estimate the missing values.

The hazard ratios were derived from the average effect across 10 augmented datasets, with the confidence intervals and significance tests taking into account the uncertainty of the imputations. The multiple imputation was performed by the MICE library within the S-Plus 2000 Guide to Statistics Volumes 1 and 2 (MathSoft, Seattle, WA, USA), and all other analyses were performed using the STATA version 7 software (STATA Corporation,
Table 1

Clinicopathological variables according to c-erbB2 status

\begin{tabular}{|c|c|c|c|c|}
\hline & AER-2-negative & HER-2-positive & e $P$ & Overall \\
\hline Total & 54 & 13 & & 67 \\
\hline \multicolumn{5}{|c|}{ Oestrogen receptor status } \\
\hline$\leq 10 \mathrm{fmol} / \mathrm{mg}$ & 25 & 10 & $0.05^{\star}$ & 35 \\
\hline$>10 \mathrm{fmol} / \mathrm{mg}$ & 29 & 3 & & 32 \\
\hline \multicolumn{5}{|l|}{ Node status } \\
\hline Negative & 36 & 8 & 0.73 & 44 \\
\hline Positive & 18 & 5 & & 23 \\
\hline \multicolumn{5}{|l|}{ Histologic grade } \\
\hline Grade I & 4 & 0 & 0.48 & 4 \\
\hline Grade II & 17 & 5 & & 22 \\
\hline Grade III & 22 & 7 & & 29 \\
\hline 'Other' & 11 & 1 & & 12 \\
\hline \multicolumn{5}{|c|}{ Nottingham Prognostic Index } \\
\hline GPG score $\leq 3.4$ & 4 & 1 & 0.61 & 6 \\
\hline MPG score 3.4-5.4 & 28 & 8 & & 40 \\
\hline PPG score > $>5.4$ & 7 & 3 & & 10 \\
\hline \multicolumn{5}{|l|}{ Age } \\
\hline$<50$ years & 19 & 8 & & 28 \\
\hline$\geq 50$ years & 35 & 5 & & 39 \\
\hline Median (range) & $56(32-80)$ & $46(37-67)$ & $0.03^{\star}$ & $55(32-80)$ \\
\hline \multicolumn{5}{|l|}{ Tumour size } \\
\hline$\leq 2 \mathrm{~cm}$ & 15 & 4 & & 19 \\
\hline$>2 \mathrm{~cm}$ & 39 & 9 & & 48 \\
\hline Median (range) & $2.5(1-5.5)$ & $2.6(1-5.3)$ & 0.76 & $2.5(1-5.5)$ \\
\hline
\end{tabular}

GPG, good prognostic group; MPG, moderate prognostic group;

PPG, poor prognostic group.

${ }^{*}$ Relationship reached significance $(P \leq 0.05)$.

\section{Results}

\section{HER-2 expression and association with} clinicopathologic factors

HER-2 immunoreactivity was evaluable in 67 (92\%) cases, and scored positively in 13 (19\%) cases (Fig. 1) using scoring of $2+$ and $3+$ as indicative of HER-2 protein overexpression. Tumours with HER-2 scores of 0 or $1+$ were assessed as negative. HER-2 expression was analysed in relation to clinicopathologic criteria (Table 1), with a significant association of HER-2 positivity with young age ( $\leq 50$ years) $(P=0.03)$ and with ER-negative $(\leq 10 \mathrm{fmol} / \mathrm{mg})$ tumours $(P=0.05)$.

\section{Association of HER-2 with subcellular localisation of p21 WAF1/CIP1}

p21WAF1/CIP1 expression measured as an IDS was analysed in the nucleus and in the cytoplasm in relation to HER-2 expression (Fig. 1). Nuclear p21WAFI/CIP1 was higher in HER-2-negative tumours with a median IDS of 7.3 (range, 0-88.5), compared with a median IDS of 2.3 (range, 0-37.5) in HER-2-positive breast cancers $(P=0.05)$ (Fig. 2). Cytoplasmic p21WAF1/CIP1 staining was significantly higher in HER-2-positive cancers with a median IDS of 95 (range, 12.5-154.5; $P=0.005$ ), com- 

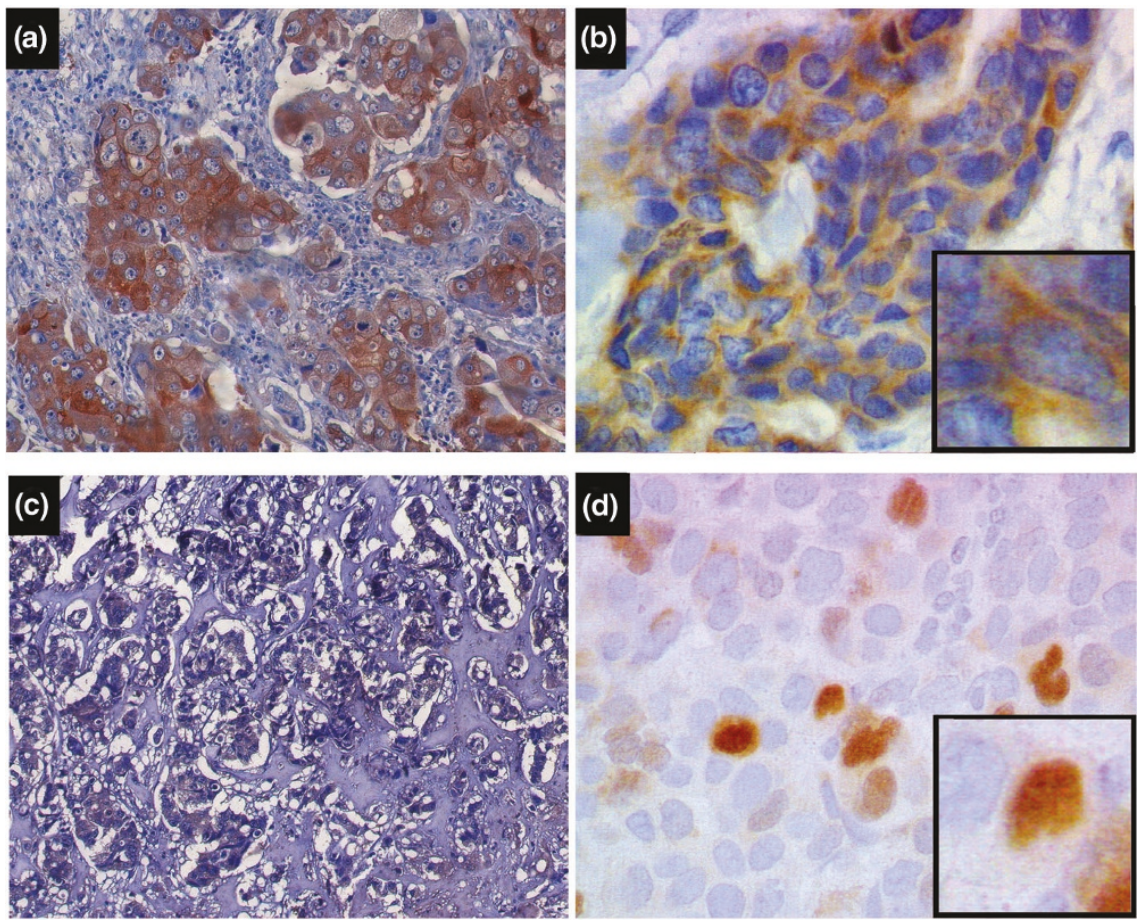

Examples of HER-2 and p21WAF1/CIP1 immunoreactivity in infiltrating ductal carcinoma of the breast. Immunostaining was performed as described in Materials and methods, and nuclei were counterstained with haematoxylin. (a) A tumour showing HER-2 overexpression, with (b) a concomitant predominance of cytoplasmic $221_{\text {WAF1/CIP1 }}$ staining and minimal or no nuclear p21WAF1/CIP1 expression. (c) A HER-2-negative tumour, with (d) a predominance of nuclear $\mathrm{p} 21_{\text {WAF1/CIP1 }}$ expression compared with cytoplasmic $\mathrm{p} 21$ WAF1/CIP1, which was proportionately less on intensity distribution scoring in 10 fields. Insets in panels (b) and (d) show higher-power views of the same fields. Magnification $\times 3-4$.

pared with HER-2-negative tumours with a median IDS of 47 (range, 0-134.6) (Fig. 2).

These results suggest that HER-2-positive tumours showed an increase in cytoplasmic p21WAF1/CIP1 of 50 IDS units, compared with a decrease of 5 IDS units for nuclear p21WAF1/CIP1. Despite proportionately lower nuclear p21WAF1/CIP1 levels on IDS, the HER-2-associated increase is far greater in terms of cytoplasmic immunoreactivity. This suggests that the association between cytoplasmic p21WAF1/CIP1 and HER-2 positivity is stronger than for nuclear $\mathrm{p} 21^{\text {WAF1/CIP1. }}$

\section{Relationship of clinicopathological factors to prognosis and the predictive potential of HER-2 and p21 WAF1/CIP1 expression}

At 9 years, disease relapses were seen in 33 patients (22 of 48 node-negative patients and 11 of 25 node-positive patients); 30 women died from breast carcinoma. The 9 -year RFS and OS were 52\% and 61\%, respectively. Poor prognostic factors such as the presence of lymph node metastases, high tumour grade, large tumour size and negative ER status were all associated with a lower percentage of patients remaining disease-free (RFS) and alive (OS) at 9 years (data not shown). The 5 -year OS of the NPI subgroups were $67 \%$ (95\% confidence interval, $19-95 \%$ ) for the good prognostic group, 78\% (95\% confidence interval, 61-88\%) for the moderate prognostic group and 40\% (95\% confidence interval, 12-67\%) for the poor prognostic group, respectively.

Univariate and multivariate analyses were used to investigate possible relationships between patient survival data and HER-2 expression, and the subcellular distribution of p21WAF1/CIP1 (Table 2). Univariate analysis showed that HER-2 was significantly associated with a decreased OS $(P=0.05)$ and a decreased RFS $(P=0.02)$ (Table 2 and Fig.3). Cytoplasmic p21WAF1/CIP was associated with a decreased OS and a decreased RFS on univariate analysis $(P=0.03)$ (Table 2$)$. The multivariate analysis was adjusted for the NPI and treatment groups (no treatment, tamoxifen, other) (Table 2). Multivariate analysis demonstrated the independent prognostic significance of cytoplasmic p21WAF1/CIP and HER-2 in relation to OS and RFS, while nuclear p21WAF1/CIP was not a prognosticator in this study.

\section{Discussion}

HER-2 enhances cancer cell growth, and a number of in vitro studies have highlighted mechanisms to explain its 


\section{Figure 2}

(a) nuclear $\mathrm{p} 21^{\text {WAFI/CIPI }}$

(b) cytoplasmic $\mathrm{p} 21^{\text {WAFI/CIPI }}$
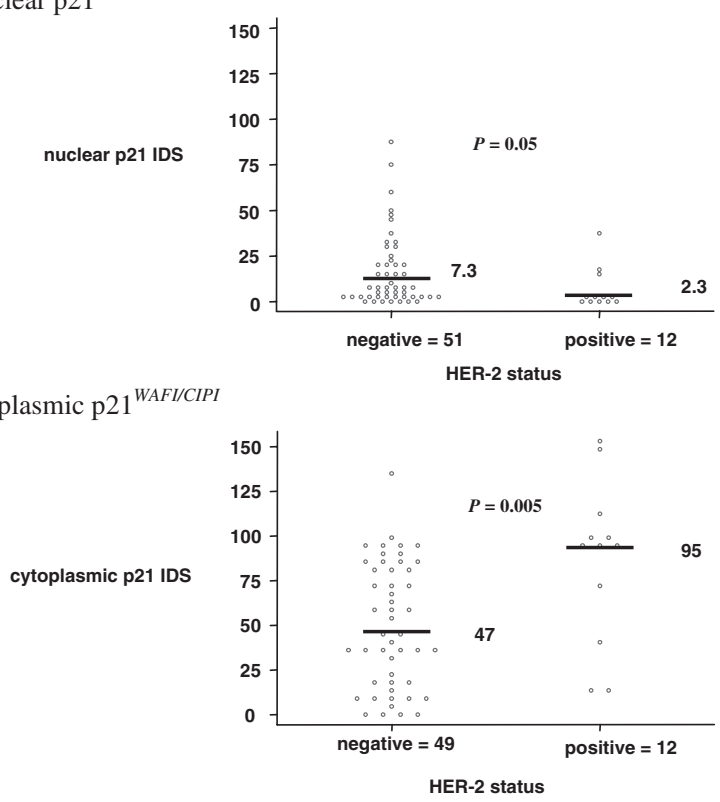

Relationship between HER-2 and p21WAF1/CIP1 localisation. Scatter plots according to HER-2 status and the subcellular localisation of p21WAF1/CIP1 measured as an intensity distribution score (IDS). HER-2 staining was analysed as described in Materials and methods.

(a) Distribution of nuclear p21WAF1/CIP1 IDS and medians according to HER-2-negative and HER-2-positive breast cancers, with patient numbers shown. (b) Cytoplasmic p21WAF1/CIP1 IDS and medians according to HER-2 status, and numbers of patients. Of the 67 patients, nuclear $\mathrm{p} 21^{\text {WAF1/CIP1 }}$ was not evaluable in four patients, or in the cytoplasm in six cases. $P$ values indicate significance. oncogenic potential $[18,19,21,29-31]$. The relevance of these mechanisms in vivo requires further investigation. Analysis of HER-2 expression in breast cancer is important in the interpretation of patient prognosis and treatment response. In this study, the immunohistochemical detection of HER-2 was in keeping with the reported frequency of protein expression in breast cancers. Despite controversy surrounding the relative value of immunohistochemistry and fluorescence in situ hybridisation to evaluate HER-2 overexpression, a recent study has shown good concordance for both tests [32].

HER-2 positivity independently predicted prognosis in this group of breast cancers, and was associated with lack of ER expression (Tables 1 and 2, and Fig. 3). Mechanisms underpinning the association of HER-2 with ER-negative tumours need to be determined, with in vitro evidence indicating a negative regulation of HER2 transcription by steroid hormones [29]. Clinical relevance of these pathways may underlie hormone resistance in HER-2-expressing breast cancers [30].

HER-2 potentiates ligand-induced intracellular signalling by targeting the Akt oncoprotein that mediates cytoplasmic PI-3K signalling [21]. Through this mechanism, HER-2 and Akt have been shown to block apoptosis in vitro by regulating $\mathrm{p} 21_{\text {WAF1/CIP1 }}$ and by enhancing $\mathrm{p} 53$ degradation [21,31]. HER-2 increases P21WAF1/CIP1 expression to inhibit the mitotic CDC2 kinase and to block Taxolinduced apoptosis [19]. Through an alternative anti-apoptotic pathway, HER-2 induces cytoplasmic p21WAF1/CIP [21]. Immunofluorescence and subcellular fractionation

Table 2

Relationships between HER-2 and p21 WAF1/CIP1 localisation and overall survival/relapse-free survival

\begin{tabular}{|c|c|c|c|c|c|c|c|}
\hline & \multirow[b]{2}{*}{$\begin{array}{l}\text { Number } \\
\text { of patients }\end{array}$} & \multicolumn{3}{|c|}{ Univariate analysis } & \multicolumn{3}{|c|}{ Multivariate analysis } \\
\hline & & $\begin{array}{c}\text { Hazard } \\
\text { ratio per } 10 \text { IDS } \\
\text { units for p21 }\end{array}$ & $\begin{array}{c}95 \% \\
\text { confidence } \\
\text { interval }\end{array}$ & $P$ & $\begin{array}{c}\text { Hazard } \\
\text { ratio per } 10 \text { IDS } \\
\text { units for p21 }\end{array}$ & $\begin{array}{c}95 \% \\
\text { confidence } \\
\text { interval }\end{array}$ & $P$ \\
\hline \multicolumn{8}{|l|}{$\begin{array}{l}\text { Overall survival } \\
\text { p21 }\end{array}$} \\
\hline p21 nucleus & 64 & 0.96 & $0.77,1.19$ & 0.70 & 0.96 & $0.75,1.22$ & 0.73 \\
\hline p21 cytoplasm & 63 & $1.12^{\star}$ & $1.01,1.25$ & $0.03^{*}$ & $1.15^{\star}$ & $1.03,1.28$ & $0.01^{*}$ \\
\hline HER-2 $(2+/ 3+$ versus $0 / 1+)$ & 63 & $2.26^{\star}$ & $1.00,5.27$ & $0.05^{\star}$ & $3.14^{*}$ & $1.15,8.64$ & $0.03^{\star}$ \\
\hline \multicolumn{8}{|l|}{$\begin{array}{l}\text { Relapse-free survival } \\
\text { p21 }\end{array}$} \\
\hline p21 nucleus & 64 & 1.01 & $0.84,1.22$ & 0.89 & 1.03 & $0.84,1.25$ & 0.80 \\
\hline p21 cytoplasm & 63 & $1.12^{\star}$ & $1.01,1.24$ & $0.03^{*}$ & $1.15^{\star}$ & $1.02,1.28$ & $0.02^{*}$ \\
\hline HER-2 $(2+/ 3+$ versus $0 / 1+)$ & 63 & $2.60^{*}$ & $1.19,5.71$ & $0.02^{*}$ & $4.08^{\star}$ & $1.60,10.39$ & $0.003^{*}$ \\
\hline
\end{tabular}

Hazard ratios, confidence intervals and $P$ values are given for the results of both the univariate analyses and the multivariate analyses. For univariate and multivariate analyses, the hazard ratio is given for nuclear and cytoplasmic $\mathrm{p} 21^{W A F 1 / C I P 1}$ per 10 unit increase in intensity distribution score (IDS), along with the $95 \%$ confidence interval. The hazard ratio and confidence interval for HER-2 relates to $2+/ 3+$ versus $0 / 1+$. Patients with ductal, lobular or 'mixed' cancer were included where the marker data was available. The multivariate analysis is adjusted for the Nottingham Prognostic Index (NPI) (nodes, grade and size) and for treatment (tamoxifen/chemotherapy/no treatment), with the NPI based on imputed grades and tumour sizes where the relevant data were missing as described in the statistical methods. 


\section{Figure 3}

(a) Relationship between HER-2 and overall survival

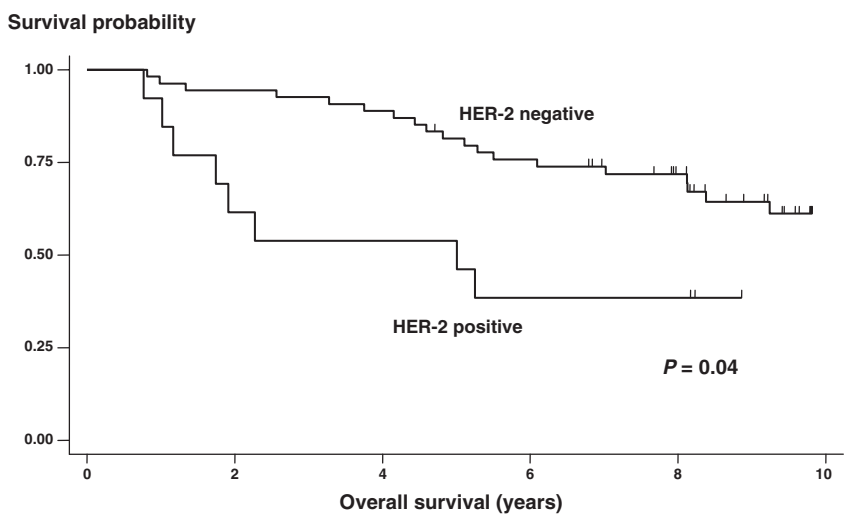

(b) Relationship between HER-2 and relapse-free survival

Survival probability

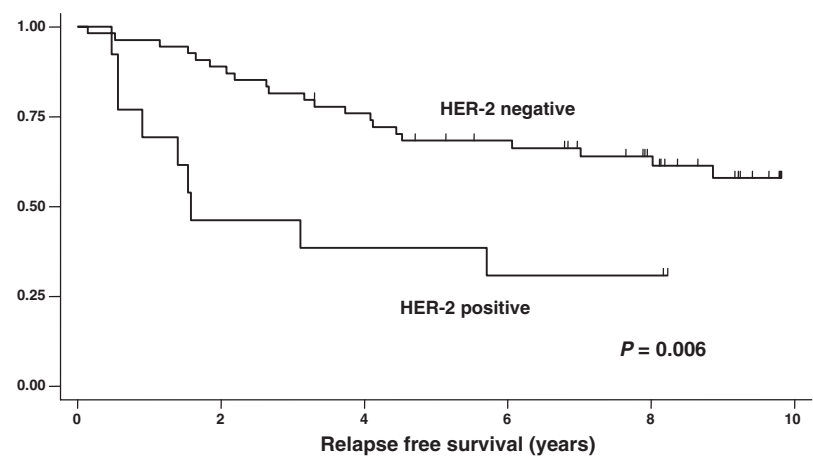

Relationship between HER-2 and prognosis in 67 patients using the log-rank test. (a) Overall survival curves according to HER-2 status, classified as negative or positive according to Materials and methods. (b) Relapse-free survival curves according to HER-2 expression. Significant $P$ values are indicated in bold.

have previously demonstrated cytoplasmic p21WAF1/CIP1 in cell lines characterised by transformation, anchorage independence and anti-apoptosis [13-16].

Predominant cytoplasmic p21WAF1/CIP1 has been detected immunohistochemically in breast tumours and in ovarian tumours $[15,17]$. Previous studies of breast carcinoma have reported the exclusive nuclear localisation of p21WAF1/CIP1 [33-35]. In our study, cytoplasmic p21WAF1/CIP1 staining was evident as previously reported $[33,36,37]$ and was based on the method of microwave antigen retrieval (Fig. 1b) using an alkaline buffer (Trisbuffered saline/EDTA, pH9.0), rather than the acidic citrate buffer (pH6.0) [17,34,35]. This series of breast cancers shows an important association between HER-2 and increased cytoplasmic p21WAF1/CIP1 to substantiate in vitro findings (Figs 1 and 2) [21]. An inverse association between the HER-2 breast tumours and nuclear p21WAF1/CIP1 further implies the ability of HER-2 to mislocalise p21WAF1/CIP1. Nuclear p21WAF1/CIP1 is required to preferentially inhibit cyclin/CDK complexes to ensure DNA repair and growth suppression of transformed cells. This process is determined by a carboxyterminal nuclear localisation signal, while mechanisms underlying nuclear export of $\mathrm{p} 21^{W A F 1 / C I P 1}$ remain to be determined. In vitro, active phosphorylated Akt binds p21WAF1/CIP1 and phosphorylates threonine 145 in the nuclear localisation signal to produce cytoplasmic p21WAF1/CIP1 [21]. In a preliminary series of five breast cancers, immunohistochemical detection of phosphorylated Akt was associated with p21WAF1/CIP1 in both the nucleus and the cytoplasm, suggesting an association with HER-2 activation [21]. This implies that the relationship between HER-2 and the sub-

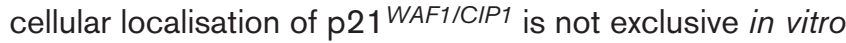
and in vivo, but reflects a preferential cytoplasmic localisation of $\mathrm{p} 21^{\text {WAF1/CIP1. }}$

Further in vivo studies are required to establish the significance of phosphorylated Akt in relation to HER-2 and subcellular localisation of p21WAF1/CIP1, with future possibilities that immunodetection of phosphorylated p21WAF1/CIP1 may imply activation of this pathway. Clinical relevance of HER-2-expressing tumours with cytoplasmic p21WAF1/CIP1 is emphasised by the independent prognostic significance of both parameters. Prognostic significance of cytoplasmic $\mathrm{p} 21^{W A F 1 / C I P 1}$ at 5 years retains its predictive potential for OS and RFS at 9 years. The combined evaluation of cytoplasmic p21WAF1/CIP1 and HER-2 positively did not increase prognostic significance in this study, due to limited patient numbers in the respective subsets. As previously reported, nuclear p21WAF1/CIP1 expression was generally low and provided no prognostic information $[17,33,35]$. Future studies will be required to address what are the best markers.

The biological implications of cytoplasmic p21WAF1/CIP1 with respect to the ability to assemble and inhibit cyclin/CDK complexes and to bind apoptosis signal-regulating kinase 1 require further investigation. Studies in cell culture suggest a loss of p53 and growth suppressor function, with inhibition of apoptosis. Subcellular localisation of $\mathrm{p} 21$ WAF1/CIP1 may have relevance underlying mechanisms of HER-2 drug resistance, with the potential for cytoplasmic p21WAF1/CIP1-expressing breast tumours to have increased chemo-resistance or hormone resistance. Small patient numbers precluded a separate analysis of treatment relapses in cytoplasmic p21WAF1/CIP1-expressing tumours. The potential to define and modify this pathway through Herceptin inhibition of HER-2 or through Iressa inhibition of HER-1 could influence downstream targets of the pathways such as Akt and p21WAF1/CIP1 [38]. The ability of HER-2 to dysregulate p21WAF1/CIP1, a key target of $\mathrm{p} 53$, is highly relevant in the context of p53 
wild-type cancers, in which growth suppression and apoptosis may be inhibited through mislocalisation of p21 WAF1/CIP1.

\section{Conclusion}

These presented findings indicate that HER-2 expression may influence tumour outcome through a mechanism regulating the subcellular localisation of p21WAF1/CIP1 to produce a cytoplasmic distribution resulting in a loss of its tumour suppressor functions. Cytoplasmic p21WAF1/CIP1 predicts poor prognostic tumours and may have a role in HER-2-mediated drug resistance, with the potential for future therapeutic manipulation by Herceptin. Cytoplasmic p21WAF1/CIP1 may conceivably be a surrogate marker for HER-2 signalling in vivo to classify clinical subgroups of patients most likely to benefit from Herceptin, such that Herceptin inhibition of the pathway could relocate p21WAF1/CIP1 to the nucleus. A cytoplasmic to nuclear relocalisation of $\mathrm{p} 21^{W A F 1 / C I P 1}$ could be a useful biological endpoint to analyse the potential efficacy of Herceptin. Other growth factor pathways involving insulin have recently been implicated in Herceptin resistance, suggesting biological modifications of the Herceptin response $[20,39]$. Increasingly, there is a rationale for identifying biological markers of drug responsiveness.

\section{Competing interests}

None declared.

\section{Acknowledgements}

ZE Winters and RD Leek contributed equally to this work. This work was supported by Cancer Research UK and the Nuffield Foundation (Fellowship to ZEW).

\section{References}

1. Hynes NE, Horsch K, Olayioye MA, Badache A: The ErbB receptor tyrosine family as signal integrators. Endocr Relat Cancer 2001, 8:151-159.

2. Ménard S, Tagliabue E, Campiglio M, Pupa, SM: Role of HER2 gene overexpression in breast carcinoma. J Cell Physiol 2000, 182:150-162.

3. Marshall CJ: Specificity of receptor tyrosine kinase signaling: transient versus sustained extracellular signal-regulated kinase activation. Cell 1995, 80:179-185.

4. Chung J, Grammer TC, Lemon KP, Kazlauskas A, Blenis J: PDGF-and insulin-dependent pp70S6k activation mediated by phosphatidylinositol-3-OH kinase. Nature 1994, 370:7175.

5. Downward J: Mechanisms and consequences of activation of protein kinase B/Akt. Curr Opin Cell Biol 1998, 10:262-267.

6. $\mathrm{Da} \mathrm{Ha} \mathrm{SR}$, Brunet A, Greenberg ME: Cellular survival: a play in three Akts. Genes Dev 1999, 13:2905-2927.

7. Slamon DJ, Clark GM, Wong SG, Levin WJ, Ulrich A, McGuire WL: Human breast cancer: correlation of relapse and survival with amplification of the HER-2/neu oncogene. Science 1987, 235:177-182.

8. Kastan MB, Onyekwere O, Sidransky D, Vogelstein B, Craig RW: Participation of p53 protein in the cellular response to DNA damage. Cancer Res 1991, 51:6304-6311.

9. Brugarolas J, Chandrasekaran C, Gordon Jl, Beach D, Jacks T, Hannon GJ: Radiation-induced cell cycle arrest compromised by 21 deficiency. Nature 1995, 377:552-557.

10. Waldman T, Kinzler KW, Vogelstein B: p21 is necessary for the p53-mediated G1 arrest in human cancer cells. Cancer Res 1995, 55:5187-5190.
11. Winters ZE, Ongkeko WM, Harris AL, Norbury CJ: p53 regulates Cdc2 independently of inhibitory phosphorylation of reinforce radiation-induced G2 arrest in human cells. Oncogene 1998, 17:673-684.

12. Dulic V, Stein GH, Far DF, Reed SI: Nuclear accumulation of p21 ${ }^{\text {Cip } 1}$ at the onset of mitosis: a role of the G2/M-phase transition. Mol Cell Biol 1998, 18:546-557.

13. Poon RYC, Hunter T: Expression of a novel form of $\mathrm{p} 21^{\mathrm{Cip} 1 / \text { Waf1 }}$ in UV-irradiated and transformed cells. Oncogene 1998, 16: 1333-1343.

14. Orend G, Hunter T, Ruoslahti E: Cytoplasmic displacement of cyclin E-cdk2 inhibitors p21 Cip1 and p27 Kip1 in anchorageindependent cells. Oncogene 1998, 16:2575-2583.

15. Barboule N, Baldin V, Jozan S, Vidal S, Valette A: Increased level of p21 in human ovarian tumors is associated with increased expression of CDK2, cyclin A and PCNA. Int J Cancer 1998, 76: 891-896.

16. Asada M, Yamada T, Ichijo H, Delia D, Miyazono K, Fukumuro K, Mizutani S: Apoptosis inhibitory activity of cytoplasmic p21 Cip1/WAF1 in monocytic differentiation. EMBO $J$ 1999, 18: 1223-1234.

17. Winters ZE, Hunt NC, Bradburn MJ, Royds JA, Turley $\mathrm{H}$, Harris AL, Norbury CJ: Subcellular localization of cyclin B, Cdc2 and p21 WAF1/CIPI in breast cancer: association with prognosis. Eur $J$ Cancer 2001, 37:2405-2412.

18. Mitsuuchi $Y$, Johnson SW, Selvakumaran M, Williams SJ, Hamilton TC, Testa JR: The phosphatidylinositol 3-kinase/AKT signal transduction pathway plays a critical role in the expres-

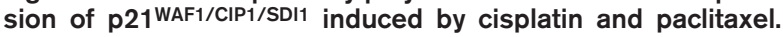
Cancer Res 2000, 60:5390-5394.

19. Yu D, Jing T, Liu B, Yao J, Tan M, McDonnell TJ, Hung M-C: Overexpression of ErbB2 blocks taxol-induced apoptosis by upregulation of p21 ${ }^{\mathrm{Cip} 1}$, which inhibits $\mathrm{p} 34^{\mathrm{Cdc} 2}$ kinase. Mol Cell 1998, 2:581-591.

20. Dupont J, Karas M, LeRoith D: The cyclin dependent kinase inhibitor p21 CIP/WAF is a positive regulator of IGF-1-induced cell proliferation in MCF-7 human breast cancer cells. J Biol Chem 2003, 278:37256-37264.

21. Zhou BP, Liao Y, Xia W, Spohn B, Lee M-H, Hung M-C: Cytoplasmic localisation of p21 Cip1/WAF1 by Akt-induced phosphorylation in HER-2/neu-overexpressing cells. Nat Cell Biol 2001, 3:245-252.

22. Galea MH, Blamey RW, Elston CW, Ellis IO: The Nottingham prognostic index in primary breast cancer. Breast Cancer Res Treat 1992, 22:207-219.

23. Kollias J, Murphy CA, Elston CW, Ellis IO, Robertson JFR, Blamey RW: The prognosis of small primary breast cancers. Eur J Cancer 1999, 35:908-912.

24. Azzopardi J: Problems in Breast Pathology. London: WB Saunders; 1979.

25. Elston CW, Ellis IO: Pathological prognostic factors in breast cancer: the value of histological grade in breast cancer: experience from a large study with long-term follow-up. Histopathology 1991, 19:403-410.

26. Rhodes A, Jasani B, Anderson E, Dodson AR, Balaton AJ: Evaluation of HER-2/neu immunohistochemical assay sensitivity and scoring on formalin-fixed and paraffin-processed cell lines and breast tumors: a comparative study involving results from laboratories in 21 countries. Am J Clin Pathol 2002, 118:408-417.

27. Van Buuren S, Boshuizen HC, Knook DL: Multiple imputation of missing blood pressure covariates in survival analysis. Stat Med 1999, 18:681-694.

28. Van Buuren S, Oudshoorn CGM: Multiple imputation by chained equations: MICE 1.0 users manual. Leiden, The Netherlands: TNO Institute for Prevention and Health. [http://web.inter.nl.net/ users/S.van.Buuren/mi/docs/Manual.pdf]

29. Nicholson RI, Hutcheson IR, Harper ME, Knowlden JM, Barrow D, McClelland RA, Jones HE, Wakeling AE, Gee JMW: Modulation of epidermal growth factor receptor in endocrine-resistant, oestrogen receptor-positive breast cancer. Endocr Relat Cancer 2001, 8:175-182.

30. Dowsett M: Overexpression of HER-2 as a resistance mechanism to hormonal therapy for breast cancer. Endocr Relat Cancer 2001, 8:191-195.

31. Zhou BP, Liao Y, Xia X, Zou Y, Spohn B and Hung M-C: HER-2/ neu induces p53 ubiquitination via Akt-mediated MDM2 phosphorylation. Nat Cell Biol 2001, 3:973-982.$$
\text { (19.95, } 55.5187-5190 .
$$ 
32. Dowsett M, Bartlett J, Ellis IO, Salter J, Hills M, Mallon E, Watters AD, Cooke T, Paish C, Wencyk PM, Pinder SE: Correlation between immunohistochemistry (HercepTest) and fluorescence in situ hybridization (FISH) for HER-2 in 426 breast carcinomas from 37 centres. J Patho/ 2003, 199:418-423.

33. Barbareschi M, Doglioni C, Veronese S, Bonzanini M, Dalla Palma $\mathrm{P}$, Harris AL, Caffo O: p21 WAF1 and p53 immunohistochemical expression in breast carcinoma may predict therapeutic response to adjuvant treatment. Eur J Cancer 1996, 32:21822183.

34. Diab SG, Yu YY, Hilsenbeck SG, Allred DC, Elledge RM: WAF1/CIP1 protein expression in human breast tumours. Breast Cancer Res Treat 1997, 43:99-103.

35. Pellikainen MJ, Pekola TT, Ropponen KM, Kataja VV, Kellokoski JK, Eskelinen MJ, Kosma V-M: p21WAF1 expression in invasive breast cancer and its association with p53, AP-2, cell proliferation, and prognosis. J Clin Patho/ 2003, 56:214-220.

36. Göhring U-J, Bersch A, Becker M, Neuhaus W, Schöndorf T: p21 waf correlates with DNA replication but not with prognosis in invasive breast cancer. J Clin Pathol 2001, 54:866-870.

37. McClelland RA, Gee JM, O'Sullivan L: p21 (WAF1) expression and endocrine response in breast cancer. J Pathol 1999, 188: 126-132.

38. Leonard DS, Hill ADK, Kelly L, Dijkstra B, McDermott E, O'Higgins $\mathrm{NJ}$ : Anti-human epidermal growth factor receptor 2 monoclonal antibody therapy for breast cancer. Br J Surg 2002, 89: 262-271.

39. Lu Y, Zi X, Zhao Y, Mascarenhas D, Pollak M: Insulin-like growth factor-I receptor signaling and resistance to trastuzumab (herceptin). J Natl Cancer Inst 2001, 93:1852-1857.

\section{Correspondence}

ZE Winters, University Department of Surgery, Bristol Royal Infirmary, University of Bristol, Marlborough Street, Bristol BS2 8HW, UK. Tel: +44 117 9283495; fax: +44 117 9252736; e-mail zoe.winters@bristol.ac.uk 